\title{
Lean Health Care: What Can Hospitals Learn from a World-Class Automaker?
}

\author{
Christopher S. Kim, мD, мвA ${ }^{1,2}$ \\ David A. Spahlinger, mD ${ }^{1}$ \\ Jeanne M. Kin, JD, MHA $^{3}$ \\ John E. Billi, MD ${ }^{1}$ \\ ${ }^{1}$ Division of General Internal Medicine, University \\ of Michigan, Ann Arbor, Michigan \\ ${ }^{2}$ Department of Pediatrics and Communicable \\ Diseases, University of Michigan, Ann Arbor, Mich- \\ igan \\ ${ }^{3}$ Department of Internal Medicine, Medical School \\ Administration, University of Michigan, Ann Arbor, \\ Michigan
}

BACKGROUND: With health care costs continuing to rise, a variety of process improvement methodologies have been proposed to address the reported inefficiencies in health care delivery. Lean production is one such method. The management philosophy and tools of lean production come from the manufacturing industry, where they were pioneered by Toyota Motor Corporation, which is viewed as the leader in utilizing these performance improvement methods. Lean has already enjoyed tremendous success in improving quality and efficiency in both the manufacturing and the service sector industries.

RESULTS: Health care systems have just begun to utilize lean methods, with reports of improvements just beginning to appear in the literature. We describe some of the basic philosophy and principles of lean production methods and how these concepts can be applied in the health care environment. We describe some of the early success stories and ongoing endeavors of lean production in various health care organizations. We believe the hospital is an ideal setting for use of the lean production method, which could significantly affect how health care is delivered to patients.

CONCLUSIONS: We conclude by discussing some of the potential challenges in introducing and implementing lean production methods in the health care environment. Lean production is a novel approach to delivering high-quality and efficient care to patients, and we believe that the health care sector can anticipate the same high level of success that the manufacturing and service industries have achieved using this approach. Hospitalists are primed to take action in delivering care of greater quality with more efficiency by applying these new principles in the hospital setting. Journal of Hospital Medicine 2006; 1:191-199. () 2006 Society of Hospital Medicine.

KEYWORDS: Iean health care, quality improvement, care standardization, process cycle, efficiency.

oyota is widely recognized as one of the most successful companies in the world. Its automobiles have consistently placed at or near the top of the quality and customer satisfaction rankings published by J.D. Power and Associates and Consumer Reports. Toyota constantly focuses on the safety and well-being of its employees and the quality of its cars through its relentless dedication to continuous improvement in everything it does. Toyota has recently become the world's number two auto manufacturer, and the company's net profit margin was more than 8 times that of the industry average. ${ }^{1}$

How has Toyota been able to achieve such remarkable results in product quality, market share, and profit margins? Jeffrey Liker, in his book The Toyota Way, described the world-renowned Toyota production system as supported by 2 pillars: continuous
The authors wish to thank the peripherally inserted central catheter (PICC) team for the use of their current and future state maps on PICC line placements that were created for the lean project. 
improvement and respect for people. The end result is a learning organization that values employee contributions and continuously strives to produce products of higher quality at lower cost. ${ }^{1,2}$ Lean production is the generic term used to describe the principles and methods of the Toyota Production System. Lean production has been implemented to improve performance in a broad array of industries, from aerospace and aluminum refining to financial services and insurance. The philosophy of lean thinking, which is derived from the Toyota Production System, is rapidly gaining a following among health care leaders, with a number of hospitals and medical groups around the country adopting a version of lean production as their systematic approach to improving quality and efficiency. In the coming years, the application of lean principles and methods could have a transformational effect on how health care is delivered, with the potential for dramatic gains in quality, safety, efficiency, and appropriateness.

\section{LEAN CONCEPTS}

To understand how lean production can be applied to improve the delivery of health care, some of the fundamental concepts and practice of lean must first be explained., ${ }^{3,4}$ The first step in a lean improvement initiative is to understand value as defined by our customers. ${ }^{5}$ In clinical care delivery, external customers include patients, families, payers, and regulators. Internal customers include physicians, nurses, clerks, and others involved in the care process. What customers value usually includes care that is of high quality, safe, efficient and appropriate. The second step typically is to go to the workplace and observe firsthand how the process now operates. ${ }^{6}$ As the flow of the process from beginning to end is seen, the observer "learns to see" and to understand the multiple areas of delay, inefficiency, and waste that may exist. ${ }^{7,8}$ A representational flowchart called a current-state value stream map (CS VSM) is created to make the work visible and to depict graphically all the individual steps necessary to complete the process from beginning to end. It is important that the CS VSM be a factual depiction of how an entire process flows created by those who actually work in that process. The CS VSM does not state any exceptions to or provide any explanations for why certain steps are taken. It does include key measures such as process time (the actual time it takes to complete a particular step of the process), lead time (the total time it takes to complete the entire process, including waiting time), and first-time quality (the percentage of time in which that step of the process is completed without defect); (see Figure 1).

In the hands of an improvement team, the current state map becomes a powerful tool that allows participants to systematically recognize and categorize waste. The CS VSM also allows workers to visualize how much opportunity there is for improving the existing process. Working from the CS VSM, the team members can identify specific areas of waste, delay, causes of error, and inefficiency. The team then brainstorms ideas for improvement, proposing how steps of the process might be combined, eliminated, error-proofed, or otherwise improved to transform waste into value from the customer's perspective. In the third step, the team seeks to achieve the "flow" state in which the steps of the process follow one another without stopping. All ideas are welcomed at this stage and are placed on the current state map itself or arrayed elsewhere for consideration. Using the ideas generated by the team, a new and better process is designed and depicted on a flow map called the future-state value stream map (FS VSM). ${ }^{9,10}$ The FS VSM represents an improved and streamlined or ideal way in which the process could be accomplished, as best the team was able to envision at this point (see Figure 2). Ideally, the process described in the FS VSM also allows customers to "pull" value when they need goods or services provided by the organization, rather than having to do the usual requesting and waiting seen in health care and other service industries. Creating processes from which customers pull what they need is the fourth step in lean design.

Once a future state map is devised and approved, the critical work of rapid deployment of an implementation plan for reaching the future state begins. An implementation plan explicitly identifies who is responsible for what aspect of implementation. Usually a senior leader or leadership group sponsoring the project is responsible for encouraging team members to think beyond their historical (and often political) limits and to support the team in overcoming barriers outside its control. As the individuals return to work and attempt to implement the new solutions, however, they will likely encounter areas of resistance and ambiguity that require creative solutions. The implementation phase focuses on and encourages the individual worker to experiment and work toward a solution that can be broadly adopted and disseminated for 


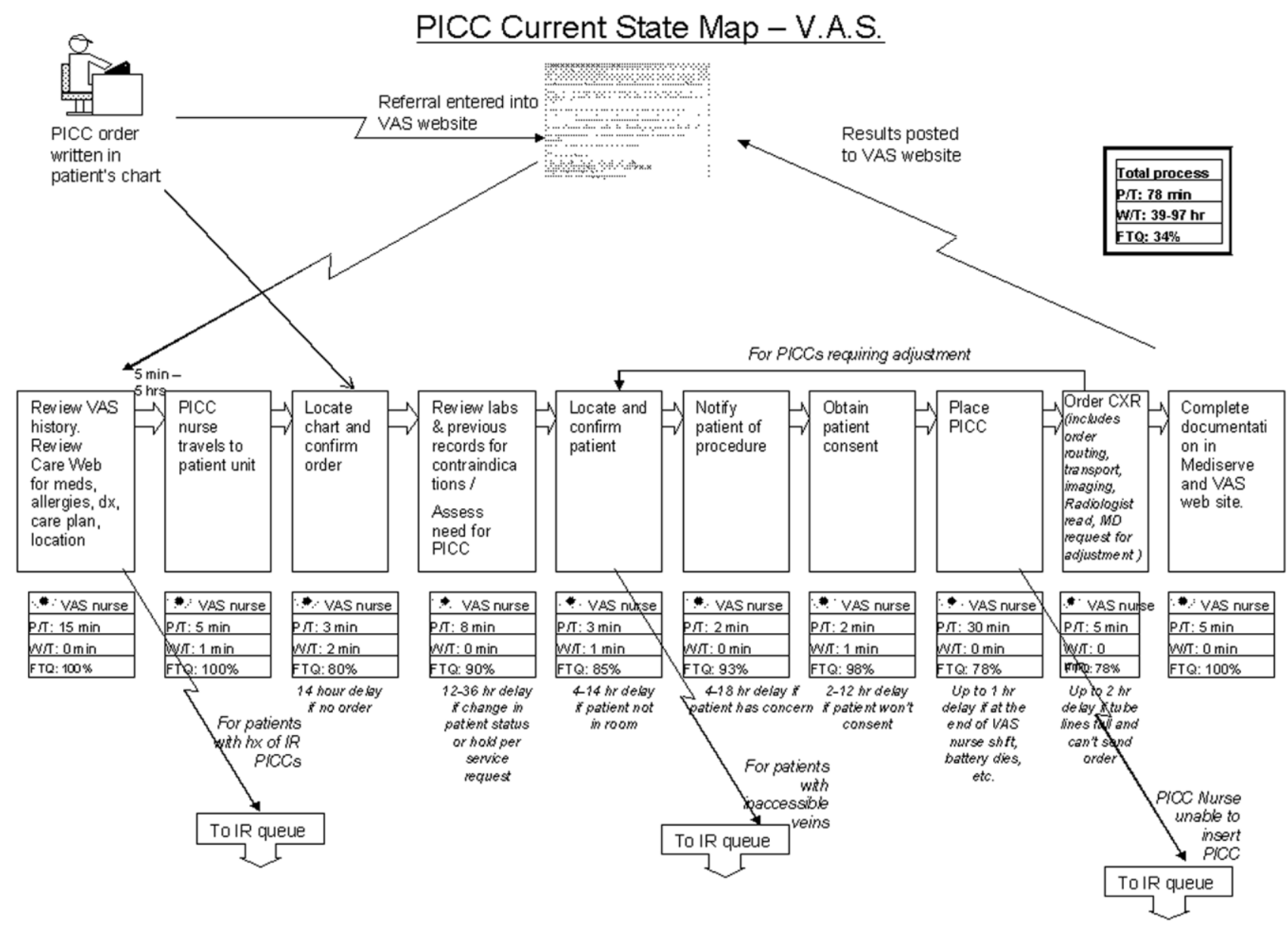

FIGURE 1. A current state value stream map depicting the work flow process of PICC nurses placing a PICC line for a patient (P/T: process time, W/T: wait time, FTQ: first-time quality, VAS: vascular access services, IR: interventional radiology). Total FTQ is calculated by multiplying all of the individual FTQ values of the entire process. See text for definitions of terms. "To IR queue" means referral to interventional radiology.

use as a standardized solution by all workers facing similar situations. ${ }^{11,12}$ Through this experimental development and dissemination of solutions, the agreed-to future-state map is revised. In this way the old future-state map plays the role of the new current-state map. There is an ongoing, continuous loop between the current- and future-state maps through implementation and testing to develop the ideal way in which the process should flow toward the final product or service (see Figure 3). The fifth step, pursuing perfection, requires this continuous loop of all workers improving everything they do, every day. The hardest of all the steps, pursuing perfection requires an organization to commit to process improvement and the elimination of defects and waste on a daily and permanent basis. ${ }^{5}$

The steps outlined above provide only the basic foundations of lean concepts, of course. A detailed description of learning about and applying lean within one's own organization requires further study and help. Readers interested in learning more about value stream mapping are referred to a workbook by Mike Rother and John Shook called Learning to See, Value Stream Mapping to Create Value and Eliminate Muda. ${ }^{4}$ Further, there are consultants with lean expertise who are available to help hospitals get started on the lean journey.

The management philosophy of lean production methods has ties to other operational and quality-improvement models such as total quality management (TQM)/continuous quality improvement (CQI), developed by W. E. Deming, and Six Sigma, developed by Motorola and General Electric. Although there are several overlapping points of 


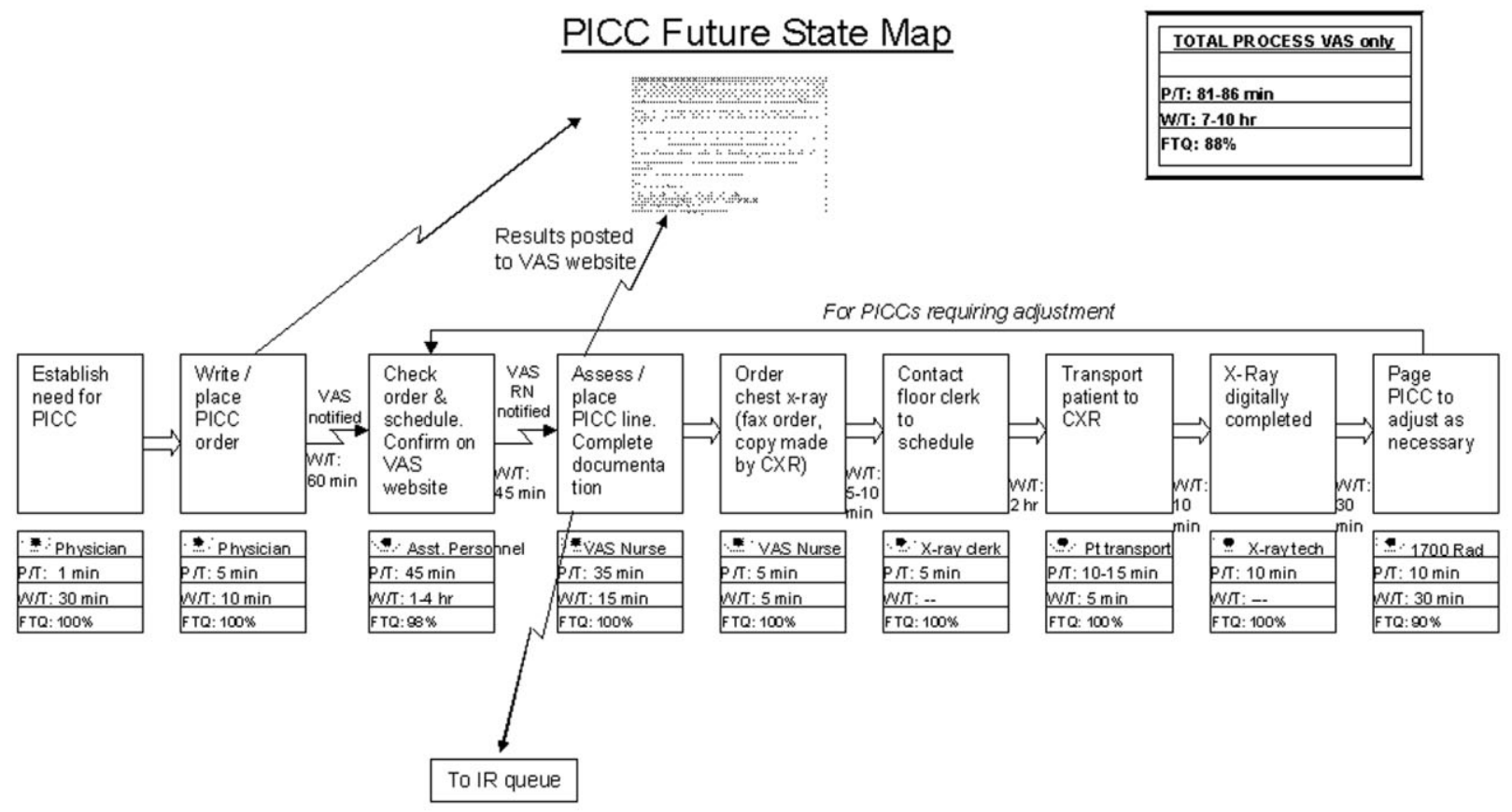

FIGURE 2. A future state value stream map describing how placing a PICC line for a patient could be improved. In this map, time spent by assisting personnel has not been added to process time, as it was assumed that work done by assisting personnel would parallel that of VAS nurses (P/T: process time, W/T: wait time, FTQ: first-time quality, VAS: vascular access services, IR: interventional radiology, 1700 rad: radiologist reading CXR for PICC line confirmation). Total FTQ is the product of the FTQ values of the individual steps. See text for definitions of terms.

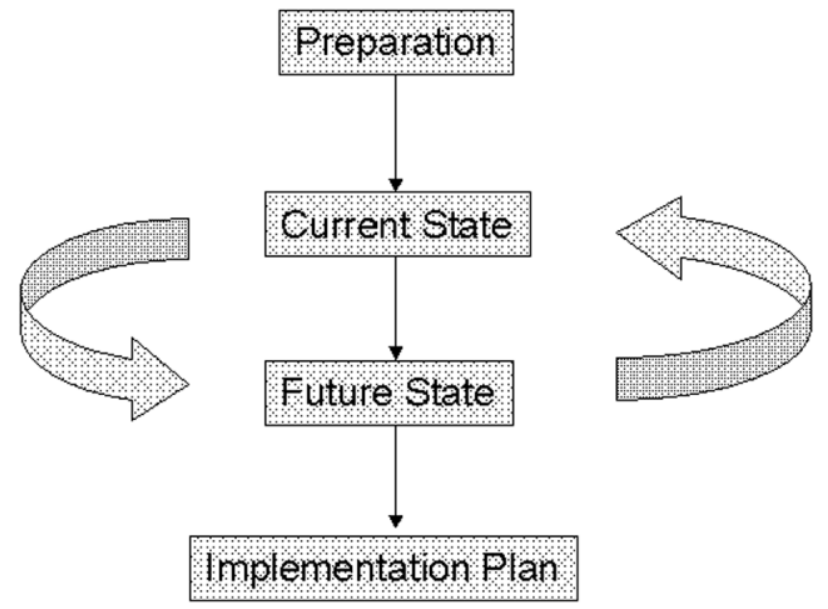

FIGURE 3. It can be seen that the practice of lean is a continuously evolving process in which new experimentation and the development of new solutions to improve the process flow leads to a new current state that in turn will develop into the new future state.

philosophy and techniques, a feature distinguishing lean from these other models is in its value stream approach to driving change and eliminating waste within the process of providing a product for the customer. Lean is unique in its focus on the specification of value from the customer's perspective and on the identification and categorization of waste and its transformation to value using specific tools. The lean approach encourages individuals within the organization (from top to bottom) "to learn to see" the flow of their product's process and thus to help to identify areas of waste, with the ultimate goal of creating a product with built-in quality with the least amount of waste. Both Six Sigma and TQM/CQI focus on the delivery of a high-quality product. Once a system has been studied and standardized, Six Sigma utilizes rigorous statistical and data measurements to drive quality improvements in product delivery. ${ }^{13}$ Total quality management/continuous quality improvement engages the entire organization in delivering a highquality product from the customer's standpoint by getting everyone in the organization involved in the continuous improvement effort. ${ }^{14}$ Lean thinking builds directly on the plan-do-check-act cycle of CQI but adds tools to identify and transform waste, 
supplies metrics of timing and resources, and, most important, focuses intently on the creation of value as defined by the customer. A more detailed comparison of lean philosophy with these other qualityimprovement management philosophies is beyond the scope of this article on the introduction of lean methods for hospitals.

\section{DOES HEALTH CARE NEED LEAN THINKERS?}

So, should health care try to emulate the successes of an automobile manufacturing company? Before answering this question, consider the following about the health care system as we know it and the significant challenges it faces.

- A key take-home message of the Institute of Medicine's 1999 report, To Err Is Human: Building a Safer Health System, was that errors are caused by poorly designed systems. ${ }^{15}$

- The Centers for Medicare and Medicaid Services (CMS) reported that the cost of health care is rising rapidly and that the rate of growth is not sustainable. $^{16}$

- Studies by the RAND Corporation demonstrated considerable variability in the practice of medicine, raising important questions about the appropriateness and necessity of some medical care and procedures. ${ }^{17,18}$

- In Crossing the Quality Chasm: a New Health System for the 21st Century, the Institute of Medicine concluded that today's health care system functions at far lower levels than it can and should and recommended 6 aims for improving the health care system: health care should be safe, effective, patient centered, timely, efficient, and equitable. ${ }^{19}$ This report is rich in detail about what the ideal health care system should look like and how application of lean philosophy and tools can help hospitals and physicians achieve that vision.

Although these challenges reflect a view of the health care system at a very macro level, the mechanism and process of driving change will need to be initiated at the more local and organizational level. Lean production focuses on the goal of continuously transforming waste into value from the customer's perspective. It provides a rigorous and systematic approach to process improvement, error proofing, and waste reduction. Manufacturing companies such as Toyota and Alcoa and financial service organizations such as Vanguard have enjoyed tremendous success in implementing lean production, reporting gains in both quality and ef- ficiency. ${ }^{11}$ It is time for health care leaders and practitioners to evaluate how lean techniques can be adapted and applied to addressing the pressing challenges of safety, quality, efficiency, and appropriateness in order to improve system reliability and timeliness. As hospitalists, we are at the forefront of these challenges and therefore are in a prime position to lead the change in how health care delivery is improved continuously using a rigorous system such as the Toyota production system.

\section{LEAN IN HEALTH CARE: EXAMPLES OF SOME EARLY RESULTS}

Lean health care is still a very novel concept to most health care institutions; however, there have been some early adopters of lean health care, and some of their experiences are described here:

- At Virginia Mason Medical Center (VMMC) in Seattle, Washington, changes implemented using lean production methods have resulted in decreased incidence of ventilator-associated pneumonia-from 34 cases with 5 deaths in 2002 to 4 cases with 1 death in 2004. This led to a cost reduction of nearly a half-million dollars. VMMC has also reported increased profit margins and improvement in space utilization at its cancer center, enabling 57\% more patients to be seen in the same allotted space; and it is now taking measures to decrease the number of medication errors by standardizing and mistakeproofing the process of ordering, delivering, and administering medications, all using lean techniques. ${ }^{12,20}$

- At Park Nicollet Health Services (PNHS) in Minneapolis, Minnesota, implementation of lean production has enabled improved patient access through flow improvements. Results include increasing the number of CT and MRI scans performed per day by 2 and 1, respectively; creating a capacity for 10 additional chemotherapy and antibiotic infusion patients per day in the cancer center; reducing the waiting time of patients from 122 to 52 minutes at the urgent care clinic; standardizing surgical instrument use by the general surgery group, which resulted in processing more than 40,000 fewer instruments each month. These improvements achieved through applying lean concepts have resulted in Park Nicollet being recognized by the American Medical Group Association (AMGA) with its toprated "Acclaim Award." ${ }^{21}$ In addition, PNHS has 
been able to achieve a record $3.9 \%$ operating margin, which equates to a $\$ 7.5$ million profit in 2004 .

- In Pittsburgh, Pennsylvania, a group of hospitals participating in the Pittsburgh Regional Healthcare Initiative (PRHI) have implemented lean concepts to minimize the risk of developing central catheterrelated bloodstream infections. Several hospitals have been able to cut the incidence of central line infections by $50 \%-90 \%$ through implementation of lean production methods. ${ }^{12}$

- At Community Medical Center in Missoula, Montana, a series of pilot projects have been initiated to test lean methods. Some of the early results have demonstrated a reduction in turnaround time for pathology reports from the anatomical pathology lab from 5 to 2 days, a reduction in the number of steps and therefore the time from medication order to treatment initiation from 4 hours to 12 minutes, and a reduction in time for unit clerks to process new physician orders from an average of 43 minutes to 10 minutes during the hospital's busiest hours. ${ }^{22}$

\section{Implications for Hospitalists}

Clinical practice in the hospital setting is process rich and provides abundant opportunities for improving the delivery of patient care. As hospitalists grow in number and increase their presence in the hospital setting, many are being asked to serve on hospital management committees to develop and implement ideas that will improve operations in the inpatient venue. As they serve in this vital capacity, hospitalists should ask themselves the following question about their practice settings:

- How often are hospital discharges prolonged because of the inability to obtain or schedule a vital test?

- How often does a planned discharge get delayed because of poor planning for what the patient may need just prior to or after discharge?

- How often do errors occur in medications received by or prescribed for patients after discharge?

- How often do preventable nosocomial infections or medical errors occur in the hospital setting?

- How often are patients readmitted to the hospital for the same illness or a related illness because of errors in communicating the accurate discharge instructions to the patient?

These are just a few examples of suboptimal care that results from suboptimal processes in many hospital settings and for which a rigorous process improvement methodology, such as lean production, could improve quality, safety, efficiency, and appropriate delivery of care. From quality and safety points of view, prevention of medical errors and nosocomial infections can lead to improved mortality and morbidity rates, as well as to significant cost savings for the health care system.

\section{THE MICHIGAN LEAN EXPERIENCE}

In the past year, the University of Michigan has begun to use lean production methods to improve the care of patients across various venues of hospitalization and flow toward discharge. Delays in placement of peripherally inserted central catheters (PICC) were associated with delays in appropriate and timely administration of intravenous medication, as well as in delays in discharges home or to extended-care facilities (ECF) for continuation of medical care post-hospitalization. Since the initiation of the lean PICC initiative, when adjusted for increased volume of demand, for 3 consecutive months $90 \%-95 \%$ of the PICC lines have been inserted within 24 hours of request. This is a remarkable achievement, given that in the previous 12 months only $50 \%-70 \%$ of PICC lines were placed within 24 hours of request. Even without adjusting for volume of demand, the lean PICC initiative has resulted in a $36 \%$ decrease in the average time to line placement and in a $50 \%$ decrease in the number of PICC referrals to interventional radiology (IR), thus decreasing the workload of a constrained resource.

As with all lean improvement projects, the entire value stream map was assessed in order to identify areas of intervention that would enhance the final product of the process for the patient (in this case, placing a PICC line as timely as possible). As we evaluated this value stream, one step in the process, occurring prior to placement of the line, appeared to be significantly wasteful: when the PICC nurse needed to search for data (such as locating a patient's chart for the order and reviewing labs and medication records) and to ensure that the patient was in his/her room and prepared for line placement. This step appeared to be inefficient use of the time of technically skilled individuals. The future state map of this process implemented the addition of an assisting individual who would ensure that these "prework" issues were prepared and completed in advance for the PICC nurses, thus making maximum use of the time of these skilled individuals in placing PICC lines, not in performing unskilled work. Another area where an intervention 
was believed beneficial was streamlining the process of chest $\mathrm{x}$-ray (CXR) ordering and reading in order to obtain PICC line confirmation. Performance of the previous process was not standardized and led to delays. The future state proposed a standard method of writing an order for a CXR, a standard method for getting that order to the radiology department, and a standard method for reading the films for dictation. This prevented the confusion and rework that had previously occurred. A last example of an intervention is that the PICC nurses began to internally defer to more experienced nurses if a less experienced nurse could not successfully place a PICC line in a patient. Previously, an unsuccessful attempt at bedside PICC placement warranted an IR referral, thus increasing the demand on an already constrained resource. This intervention by the PICC nurses drove down referrals to the IR suite by $50 \%$. Although this may have led to a small increase in rework early in the process, it has led to a significant reduction in work downstream in the process. Thus, we believe that the overall work flow process has been served well by this intervention. As depicted in Figure 3, the lean process improvement method seeks to have continuous improvement, with the old future-state map taking on the role of the new current-state map. Since the initial development of these value stream maps, we have been working toward developing and implementing new areas of intervention, which will lead to new future-state maps and to further improvement of this process, as the demand for PICC lines continues to rise.

Another critical segment in the care of hospitalized patients is the discharge process, including coordination of care to an outpatient or extended care facility (ECF) setting, which has several potential areas of disconnect that could result inpatients having untoward complications requiring rehospitalization, higher morbidity, or prolongation of suffering from their illnesses. The University of Michigan sees a tremendous opportunity to make a significant impact on patient care in this realm and has just initiated a lean project on the coordination of care. Team members on this project will be relevant process stakeholders, including those representing hospitalists, discharge planning, nursing, social work, a related home nursing company, a home infusion service, an ECF, ambulatory care, pharmacy, case management, nutrition, utilization review, patients and their families, and clinic physicians. The overall goal of the project is to optimize patient care from hospitalization to discharge and transfer of care to the outpatient setting.

\section{CHALLENGES}

The application of management philosophy and operational concepts from the manufacturing industry to health care may be a conceptual stretch for many in the health care community. Hence, both cultural and practical barriers likely will have to be overcome before lean techniques can enjoy widespread use.

On the cultural front, it will be necessary to overcome the most likely arguments against the applicability of lean manufacturing concepts to the health care sector such as "people are not automobiles" and "each patient is unique." Yet there has been considerable success in applying lean production concepts in other service industries such as insurance and financial services, with exceptionally favorable results reported, ${ }^{1,23}$ and early adopters of the lean concept in health care have credited lean management concepts with their early successes, as described above.

There are also the organizational and professional cultural differences that separate the health care industry from other sectors that have incorporated lean into their practice. Health care professionals, however, are highly dedicated and motivated to providing their patients with the best possible care and are already accustomed to constant experimentation and new data driving change in the way that care is provided. Lean production concepts and tools should not be foreign to health care professionals who already understand systems thinking.

Other challenges may come from those arguing that lean is just cutting and layoffs in disguise. It is often feared that when an organization decides to go lean, the underlying goals are to cut costs and to lay off a segment of the labor force. The term lean is often misunderstood in this respect, and it is important that the phrase be explained accurately in its context and application. Some individuals wonder whether the implementation of lean production efforts means they are working themselves out of employment. A key component of the successful application of lean production methods is assuring that as process flows and operations are improved, job descriptions and duties of individuals may be redirected, but their employment will not be lost

Finally, the multiple segments of health care are often fragmented into individually function- 
ing units operating as autonomous "silos." Lean teaches that optimizing the performance of an individual area is insufficient, that the entire process flow, which requires cooperation of multiple operating units, must be improved in order to achieve meaningful and sustained improvement in performance. This is a new way of thinking that requires behavioral change for the many who are used to thinking narrowly about the performance of their own unit. The larger organization must recognize and eliminate disincentives to breaking down the silo mentality. In health care organizations, however, providers and staff across functional departments share the same ultimate goal of delivering the very best care possible to patients within the constraint of available resources. Lean provides a management philosophy, powerful tools, and an accountability structure for working toward this goal. The organization, however, must be committed from the highest levels to making the lean transformation. ${ }^{1}$

Ultimately, health care shares with manufacturing companies such as Toyota the challenge of producing the highest-quality products (clinical outcomes) within an environment of constrained resources, while managing a complex business operation and assuring the safety and satisfaction of workers and customers (patients). Both industries need highly reliable systems that will ultimately lead to higher quality and greater safety, efficiency, and appropriateness.

\section{CONCLUSION}

The health care industry should learn about and consider adoption of lean techniques in order to improve its processes. More specifically, hospitals are prime locales for reaping the benefits of implementation of lean production, which can significantly affect how health care is delivered to patients. Toyota and other lean exemplars in the manufacturing industry have achieved a high level of success by utilizing the practice of lean. Early results from health care organizations suggest that utilizing lean production methods can lead to substantial improvements in the quality and efficiency of health care. To determine if the magnitude of success experienced by Toyota and other lean exemplars can also be achieved in the health care sector, it will be necessary to continuously test and evaluate the impact lean health care can have. In the hospital setting, where hospitalists are at the forefront of delivering care, it is incumbent on the hospitalist community to evaluate whether these techniques can make a difference in the quality, efficiency, and safety of the care provided to patients.

Lean thinking is still a novel idea to those in the health care sector, and as early adopters of this promising management model, we are very optimistic about the benefits of applying lean concepts in our hospital. Some of the first published reports and results presented on the benefits of lean in individual organizations are encouraging; however, as health care is a scientific community, we believe that future work should undergo rigorous evaluation on the benefits of lean and that such future works should be shared among the health care community through peer-reviewed and published works.

Address for correspondence and reprint requests: Christopher S. Kim, University of Michigan, Division of General Medicine, Department of Internal Medicine, 3119 Taubman Center, Box 0376, 1500 E. Medical Center Drive, Ann Arbor, MI 48109-0376; E-mail: seoungk@med.umich.edu

Received 26 October 2005; revision received 13 December 2005; accepted 18 January 2006.

\section{REFERENCES}

1. Liker JK. The Toyota Way. Madison, Wisc: McGraw-Hill; 2004.

2. Spear S, Bowen HK. Decoding the DNA of the Toyota Production System. Harv Bus Rev. 1999;77(5):97-.

3. Keyte B, Locher D. The Complete Lean Enterprise, Value Stream Mapping for Administrative and Office Processes. New York, NY: Productivity Press; 2004.

4. Rother M, Shook J. Learning to See, Value-Stream Mapping to Create Value and Eliminate Muda. Brookline, Mass: The Lean Enterprise Institute, Inc; 2003.

5. Womack JP, Jones DT. Lean Thinking, Banish Waste and Create Wealth in Your Corporation. 2nd ed. New York, NY: Free Press; 2003.

6. NAM. Getting started on the lean journey: first, take a walk! [NAM.org Web site]. Available at http://www.nam.org/ s_nam/doc1.asp?CID $=200253 \& D I D=211562$. Accessed January 2000.

7. NAM. Mapping your current state: the physical flow [NAM.org Web site]. Available at http://www.nam.org/s_nam/docl. asp? $\mathrm{CID}=200253 \& D I D=211564$. Accessed March 2000 .

8. NAM. Mapping your current state-information flow [NAM.org Web site]. Available at http://www.nam.org/ s_nam $/$ docl.asp?CID $=200253 \& D I D=211565$. Accessed May 2000 .

9. NAM. How can we create a lean value stream? [NAM.org Web site]. Available at http://www.nam.org/s_nam/ doc1.asp?CID =200253\&DID=211566. Accessed June, 2000 .

10. NAM. Creating a future state [NAM.org Web site]. Available at http://www.nam.org/s_nam/doc1.asp?CID = 200253\& $\mathrm{DID}=211567$. Accessed November 2000 . 
11. Spear SJ. The health factory. New York Times. August 29, 2005; sect 15.

12. Spear SJ. Fixing health care from the inside, today. Harv Bus Rev. 2005;83(9):78-91.

13. Six Sigma - what is Six Sigma? Available at http://www.isixsigma.com/sixsigma/six_sigma.asp. Accessed 2005.

14. Overview of the Continuous Quality Improvement Program. 2005. Available at http://www.med.umich.edu/i/exec/cqi/ overview.htm. Accessed 2005.

15. Kohn LT, Corrigan J, Donaldson MS, eds. To Err Is human: Building a Safer Health System. Washington, DC: National Academy Press; 2000.

16. McClellan MB. Testimony of Mark B. McClellan, MD, PhD, Administrator, before the House Ways and Means Subcommittee on Health on Value-Based Purchasing for Physicians under Medicare. Washington, DC: Centers for Medicare \& Medicaid Services; July 21, 2005.

17. Chassin MR, Kosecoff J, Park RE, et al. Does inappropriate use explain geographic variations in the use of health care services? A study of three procedures.[see comment]. JAMA. 1987;258:2533-2537.

18. Chassin MR, Brook RH, Park RE, et al. Variations in the use of medical and surgical services by the Medicare population. N Engl J Med. 1986;314(5):285-290.

19. Committee on Quality Health Care in America, Institute of Medicine. Crossing the Quality Chasm: a New Health System for the 21st Century. Washington, DC: National Academy Press; 2001.

20. Institute for Healthcare Improvement. Going Lean in Health Care. White Paper. Boston, MA: Institute for Healthcare Improvement; January and February 2005.

21. Lean Production at Park Nicollet. Available at http:// www.parknicollet.com/media/leanProduction.cfm. Accessed March, 2005.

22. Jimmerson C, Weber D, Sobek DK 2nd. Reducing waste and errors: piloting lean principles at Intermountain Healthcare. $J t$ Comm J Qual Patient Saf. 2005;31(5):249-257.

23. Swank CK. The lean service machine. Harv Bus Rev. 2003; 81(10):123-129, 38. 